\title{
PERENCANAAN SISTEM DRAINASE PERUMAHAN THE GREENLAKE SURABAYA
}

\author{
Riska Wulansari, Edijatno, dan Yang Ratri Savitri . \\ Jurusan Teknik Sipil, Fakultas FTSP, Institut Teknologi Sepuluh Nopember \\ Jl. Arief Rahman Hakim, Surabaya 60111 \\ Email : riska.wulansari.its@gmail.com
}

\begin{abstract}
Abstrak - Perumahan The Greenlake terletak di Jl. Raya Wiyung-Menganti, Surabaya. Kawasan ini dahulu adalah daerah irigasi sehingga terdapat saluran cacing (saluran irigasi). Pada saat ini saluran irigasi dialihfungsikan sebagai saluran drainase perkotaan. Saluran itu adalah saluran Taman Citra 1. Dalam sistem drainase perumahan The Greenlake, saluran ini diharapkan mampu untuk menampung limpasan air wilayah utara. Untuk kawasan The Greenlake wilayah selatan, direncanakan long storage melalui saluran sekunder (site drain). Langkah yang dilakukan untuk memecahkan masalah ini adalah perumusan masalah, perumusan metode yang digunakan dan pengumpulan data yang terdiri atas data hidrologi dan data hidrolika. Berdasar pada analisa data hidrologi yaitu data curah hujan didapatkan debit rencana. Selanjutnya, hasil perhitungan ini digunakan utnuk merancang dimensi saluran dalam sistem drainase perumahan The Greenlake, termasuk perhitungan kapasitas long storage dan saluran Taman Citra 1. Berdasar pada hasil perhitungan, dapat disimpulkan bahwa dimensi saluran tersier mempunyai dimensi lebar = kedalaman sebesar 0,50 meter; saluran sekunder 0,80 meter; saluran primer 1,00 meter. Fasilitas drainase yang dibutuhkan untuk long storage 1 meliputi dua buah pintu air dengan dimensi 1,20 meter x 2,00 meter dan satu buah pompa. Untuk long storage 2 meliputi satu buah pintu dengan dimensi 1,00 meter x 1,00 meter dan dua buah pompa. Normalisasi diperlukan pada beberapa penggal saluran Taman Citra 1 yaitu pada P4-P5, P7-P8, dan P8-P9.
\end{abstract}

Kata kunci-Perumahan The Greenlake Surabaya, Saluran Taman Citra 1, long storage

\section{PENDAHULUAN}

Pengembangan kawasan perumahan The Greenlake Surabaya terletak di Surabaya Barat dengan luas area $\pm 120.720 \mathrm{~m}^{2}$, lahan kawasan tersebut merupakan daerah rendah dan datar yang berupa bekas lahan sawah. Kondisi saat ini adalah lahan kosong dengan urugan tanah. Saluran drainase di beberapa lokasi tepi jalan telah dipersiapkan untuk mengalirkan sementara limpasan air hujan. Dengan adanya rencana pembangunan kawasan perumahan tersebut, maka akan mempengaruhi kondisi sistem drainase disekitar perumahan dan juga mengakibatkan berkurangnya lahan terbuka yang berfungsi sebagai resapan air hujan. Oleh karena itu, sistem jaringan drainase yang ada di perumahan TheGreenlake Surabaya perlu direncanakan dengan baik agar air hujan yang turun di kawasan perumahan tersebut tidak langsung dibuang ke rencana Saluran Sekunder melainkan ditampung terlebih dahulu di dalam kawasan. Selain itu, di kawasan perumahan ini terdapat saluran cacing (saluran irigasi) yang diperkenankan tetap difungsikan sebagai saluran kota, yaitu Saluran Taman Citra 1. (sumber : Dinas Pekerjaan Umum Bina Marga \& Pematusan) Kondisi kawasan, dimana Saluran Taman Citra 1 seperti pada Gambar
1 Siteplan rencana jaringan drainase kawasan perumahan The Greenlake Surabaya. Saluran Taman Citra 1 membagi site plan perumahan menjadi wilayah utara dan selatan. Wilayah utara direncanakan membuang limpasan permukaan di Saluran Taman Citra 1 dan untuk wilayah selatan direncanakan membuang limpasan permukaan di Rencana Saluran Sekunder (site drain). Kondisi eksisting Saluran Taman Citra 1 semakin ke hilir semakin kecil, dimana bagian hilir dinamakan Saluran Banjar Melati yaitu yang terdapat di Perumahan Safira dan Prambanan. Kondisi saluran tersebut tidak memungkinkan melakukan pelebaran lagi. Sehingga perlu perhitungan yang teliti terkait debit limpasan yang diperkenankan menuju Saluran Taman Citra 1 ini. Supaya tidak menggenangi wilayah dalam dan luar kawasan. Selain itu, wilayah selatan yang dipengaruhi besarnya limpasan permukaan pada suatu catchment area tersebut (lihat Gambar 1) dialirkan ke long storage dahulu. Hal ini berdasarkan, diberlakukannya peraturan yang menetapkan bahwa setiap adanya pembangunan harus diikuti dengan penyelesaian banjir disekitar wilayah tersebut (PERDA Kota Surabaya Nomor 3 Tahun 2007 Tentang Rencana Tata Ruang Wilayah Kota Surabaya), dengan kata 
lain bahwa setiap ada pengajuan ijin dari pengembang maka pengembang lahan pada kawasan pembangunan perumahan The Greenlake Surabaya. Dan juga perlu ditinjau lebih teliti kemampuan dari sistem drainaseuntuk menampung limpasan air hujan dikawasan yang terkait perumahan TheGreenlake Surabaya tersebut harus turut serta berpartisipasi dalam penyelesaian banjir di sekitar wilayah.Dari kondisi eksisting diatas disimpulkan bahwa perlu perencanaan teliti supaya dapat diselesaikan masalah genangan atau banjir akibat alih fungsi.

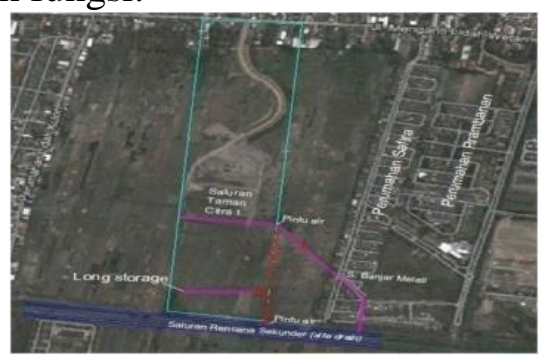

\section{Gambar 1Lokasi Pembangunan Perumahan The Greenlake}

\section{METODOLOGI}

\subsection{Metode Perencanaan}

Metode perencanaan disusun untuk mempermudah pelaksanaan perencanaan, guna memperoleh pemecahan masalah sesuai dengan tujuan perencanaan yang telah ditetapkan yaitu prosedur kerja yang sistematis, teratur dan tertib sehingga dapat dipertanggung jawabkan secara ilmiah.

2.1.1. Studi Literatur

Analisis teori-teori dari berbagai literatur mengenai perencanaan saluran dan permasalahanpermasalahan yang berkaitan dengan perencanaan drainase serta data-data yang mendukung dari berbagai media yang berhubungan dengan sistem drainase yang terdapat di Perumahan TheGreenlake Surabaya.

Pengumpulan Data

Pengumpulan data diperoleh dari data primer dan sekunder

Data primer

Teknik pengumpulan data dengan melakukan peninjauan lapangan langsung. yaitu : Kondisi wilayah daerah pengaliran (DAS)

Data sekunder

Data sekunder adalah data yang diperoleh tanpa melakukan pengamatan secara langsung atau data yang sudah ada yang diberikan oleh instansi terkait, yaitu Site Plan kawasan perumahan dan data curah hujan

2.1.3. Sistematika Penyelesaian Masalah

- Analisa Hidrologi

- Analisa Hidrolika

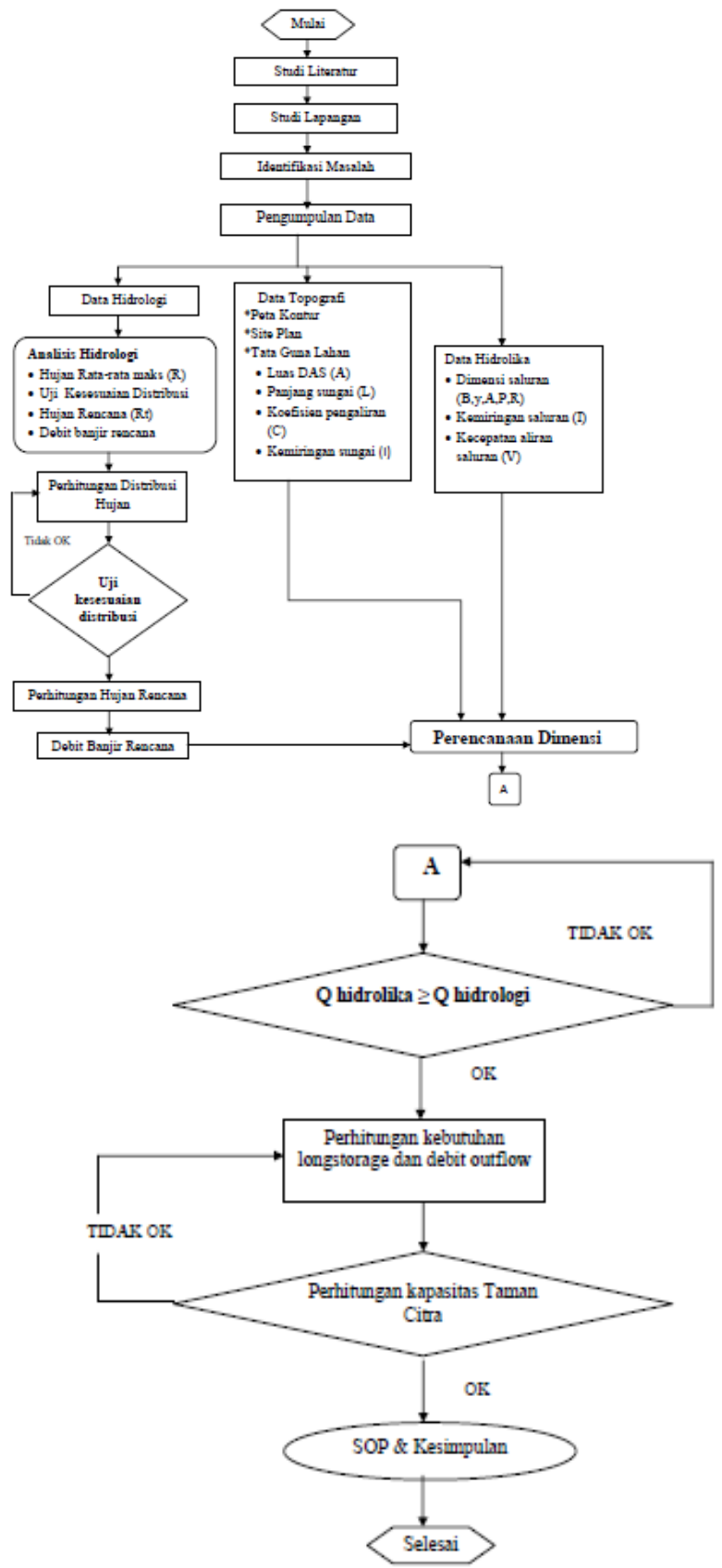

Gambar 2 Flow Chart Tugas Akhir 


\section{HASIL PEMBAHASAN}

\section{A. Analisa Data Curah Hujan}

Data curah hujan harian yang tersedia sebanyak 24 tahun (1990-2013), data ini terlebih dahulu dilakukan analisa perhitungan nilai hujan rata-rata sebelum dilakukan perhitungan statistik. Data hujan pada perencanaan sistem drainase kawasan perumahan The Greenlake ini berasal dari satu buah stasiun pengamatan, yaitu stasiun hujan Kebon Agung.

\section{B. Analisa Distribusi Probabilitas}

Untuk mencari tinggi hujan rencana periode ulang tertentu dilakukanlah analisa distribusi probabilitas. Dalam analisa distribusi probabilitas ini, dilakukan dengan empat metode distribusi, yaitu metode Gumbel, Normal, Log Normal, dan Log Pearson Type III. Dan berdasarkan persyaratan parameter statistik yang memenuhi adalah Distribusi Normal

Tabel 3.1. Nilai tinggi hujan rencana periode ulang Distribusi Normal.

\begin{tabular}{|c|c|}
\hline $\begin{array}{c}\text { Hujan Rencana } \\
\text { Periode } \\
\text { Ulang }\end{array}$ & Distribusi Probabilitas \\
\cline { 2 - 2 } & Normal \\
\hline $\mathrm{X}_{2}$ & 98,25 \\
\hline $\mathrm{X}_{5}$ & 109,411 \\
\hline $\mathrm{X}_{10}$ & 115,257 \\
\hline
\end{tabular}

*Sumber : Hasil Perhitungan

Tabel 3.2 Persyaratan parameter statistik

\begin{tabular}{|l|l|l|l|l|}
\multicolumn{5}{|c}{ Suatu distribusi } \\
\hline No & Distribusi & Persyaratan & Hasil & Ket. \\
\hline 1 & Gumbel & $\begin{array}{l}\mathrm{Cs}=1,14 \\
\mathrm{Ck}=5,4\end{array}$ & $\begin{array}{l}\mathrm{Cs}=-0,027 \\
\mathrm{Ck}=2,662\end{array}$ & $\begin{array}{l}\text { Kurang } \\
\text { Kurang }\end{array}$ \\
\hline 2 & Normal & $\mathrm{Cs} \approx 0$ & $\mathrm{Cs}=-0,027$ & Mendekati \\
& & $\mathrm{Ck} \approx 3$ & Mendekati \\
\hline 3 & Log Normal & $\begin{array}{l}\mathrm{Cs}=\mathrm{Cv}^{3}+3 \mathrm{Cv} \\
\mathrm{Ck}=\mathrm{Cv}^{8}+6 \mathrm{Cv}^{6}+\end{array}$ & $\begin{array}{l}\mathrm{Cs}=-0,78=0,09 \\
\mathrm{Ck}=2,94=3,01\end{array}$ & $\begin{array}{l}\text { Mendekati } \\
\text { Kurang }\end{array}$ \\
& & $15 \mathrm{Cv}^{4}+16 \mathrm{Cv}^{2}+3$ & & \\
\hline 4 & Log Pearson & Selain dari nilai diatas & $\mathrm{G}=-0,773$ & Fleksibel \\
& III & $\mathrm{Ck}=2,908$ & \\
\hline
\end{tabular}

*Sumber : Hasil Perhitungan

\section{Uji Kecocokan Distribusi Probabilitas}

Uji kecocokan ini bertujuan untuk mengecek apakah hasil dari distribusi probabilitas dapat diterima atau tidak untuk perhitungan lebih lanjut. Dapat dilakukan dengan dua metode yaitu metode Chi-Kuadrat dan Smirnov Kolmogorof. Hasil perhitungan dapat dilihat pada tabel berikut :
Tabel 3.2. Nilai uji kecocokan chi-kuadrat dan smirnov kolmogorof

\begin{tabular}{|c|c|c|}
\hline \multirow{3}{*}{ Persamaan } & \multicolumn{2}{|c|}{ Uji Kecocokan } \\
\cline { 2 - 3 } Distribusi & Chi-Kuadrat & Smirnov Kolmogorof \\
& $\mathrm{dk}=3, \alpha=5 \%$ & $\mathrm{n}=24, \alpha=5 \%$ \\
& $\mathrm{X}_{2}<\mathrm{X}_{2} \mathrm{cr}$ & $\Delta \mathrm{P}$ maks $<\Delta \mathrm{P}$ cr \\
\hline Normal & $5<7,815$ & $0,135<0,274$ \\
\hline
\end{tabular}

*Sumber : Hasil Perhitungan

\section{Perhitungan Dimensi Saluran}

Perhitungan dimensi saluran drainase pada kawasan perumahan The Greenlake dihitung dalam satu DAS yang dibagi beberapa Sub-DAS, antara lain kavling/rumah, jalan, dan taman. Dalam perhitungan ini tinggi hujan periode ulang yang dipakai adalah tinggi hujan periode ulang 5 tahun $\left(\mathrm{R}_{5}\right)$. Perencanaan dimensi saluran ini terdiri dari beberapa jenis saluran, yaitu saluran tersier, sekunder, dan primer. Saluraniniakan direncanakan dengan dimensi box culvert yang tersedia ada di pasaran. Untuk mendimensi saluran kawasan perumahan ini, dilakukan analisa cara coba-coba (trial error) dengan acuan selisih dari debit hidrolika dan debit hidrologi mendekati nol.Setelah setiap dimensi saluran diketahui maka direncanakan dimensi yang sesuai dengan jenis salurannya (tersier, sekunder, primer).

Tabel 3.3. Hasil perhitungan dimensi saluran perumahanThe Greenlake

\begin{tabular}{|c|c|c|c|c|c|}
\hline No & $\begin{array}{c}\text { Penampang } \\
\text { Saluran }\end{array}$ & $\begin{array}{c}\text { Jenis } \\
\text { Saluran }\end{array}$ & $\begin{array}{c}\text { Lebar (b) } \\
\mathrm{m}\end{array}$ & $\begin{array}{c}\text { tinggi }(\mathrm{h}) \\
\mathrm{m}\end{array}$ & $\begin{array}{c}\mathrm{hn} \\
\mathrm{m}\end{array}$ \\
\hline 1 & Persegi & Tersier & 0,5 & 0,5 & 0,26 \\
\hline 2 & Persegi & Sekunder & 0,8 & 0,8 & 0,43 \\
\hline 3 & Persegi & Primer & 1 & 1 & 0,55 \\
\hline
\end{tabular}

*Sumber : Hasil Perhitungan

Perhitungan Limpasan Hujan ke Long storage Kawasan perumahan The Greenlake Surabaya dibagi menjadi dua yaitu wilayah utara dan selatan. Wilayah utara direncanakan membuang limpasan permukaan di Saluran Taman Citra 1, dimana saluran Taman Citra 1 yang ada di dalam kawasan perumahan The Greenlake diberi fasilitas pintu air sebelum terkoneksi dengan saluran taman citra 1 yang berada di luar kawasan. Untuk memudahkan penyebutan, saluran Taman Citra 1 yang ada dalam kawasan Perumahan disebut dengan long storage 1. Wilayah selatan direncanakan membuang limpasan permukaan di long storage 2. Perhitungan masing-masing limpasan yang terjadi di long storage akan dianalisis menggunakan hidrograf. Hal ini 
dilakukan untuk mengetahui besar debit dan volume limpasan air yang mampu ditampung dan dibuang oleh masing-masing long storage tersebut. Data dan perhitungannya adalah sebagai berikut :

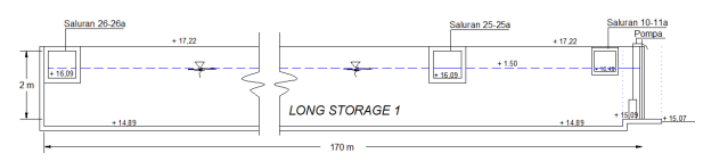

Gambar 2.Kondisi long storage1

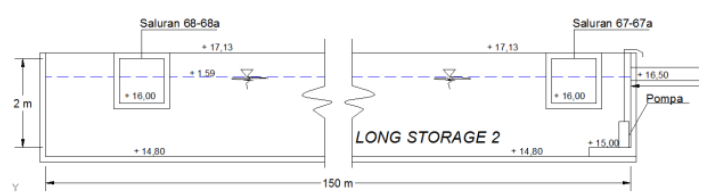

Gambar 3.Kondisi long storage 2

Keadaan long storage dianlisis pada saat musim hujan dengan volume tampungan yang sudah ada airnya, yaitu setinggi $20 \mathrm{~cm}$ dari dasar long storage, volume tampungan yang sudah ada tersebut berasal dari air kotor kawasan tersebut dan air hujan.Berikut adalah analisis perhitungan hidrograf untuk long storage 1 :

Tabel 3.4. Perhitungan hidrograf limpasan yang masuk long storage 1 (td = 28 menit)

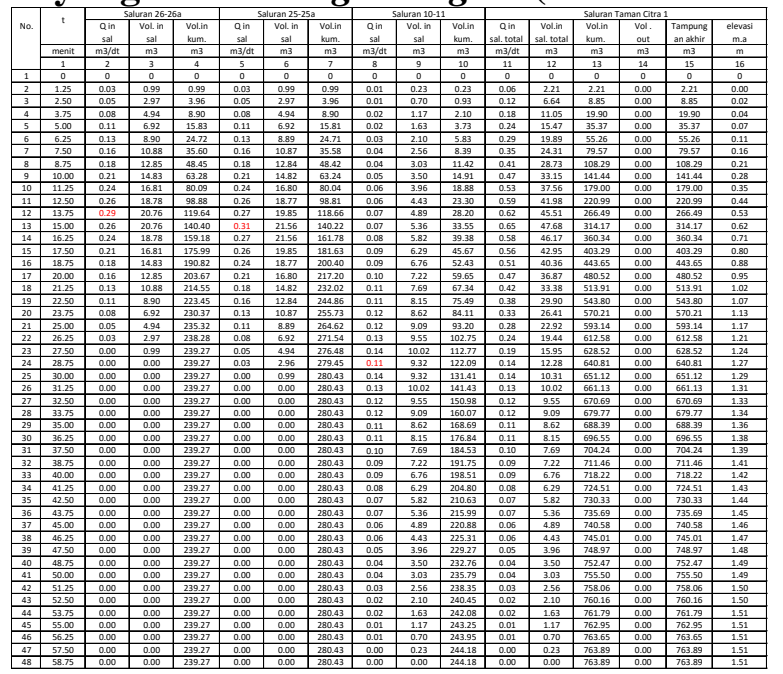

*Sumber : Hasil Perhitungan

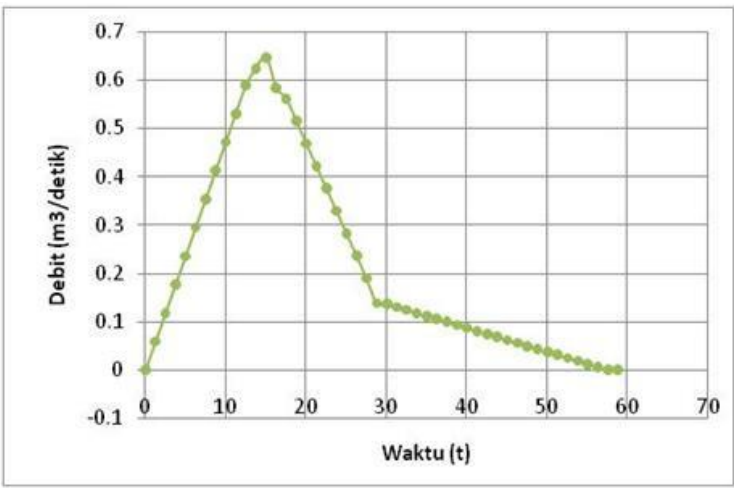

Grafik 3.1 Debit limpasan menujulong storage 1 (Saluran Taman Citra 1) [td=28 menit]

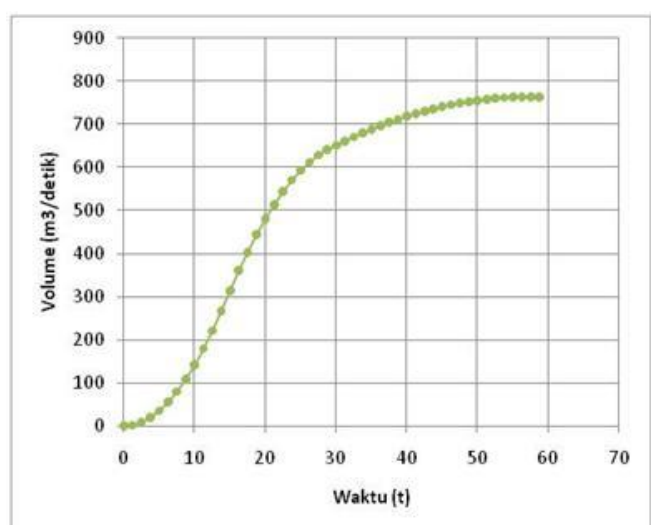

Grafik 3.2 Volume limpasan menuju long storage 1 (Saluran Taman Citra 1) $[\mathrm{td}=\mathbf{2 8}$ menit]

Tabel 3.5. Perhitungan Volume Limpasan yang masuk long storage 1 (td = 38 menit)

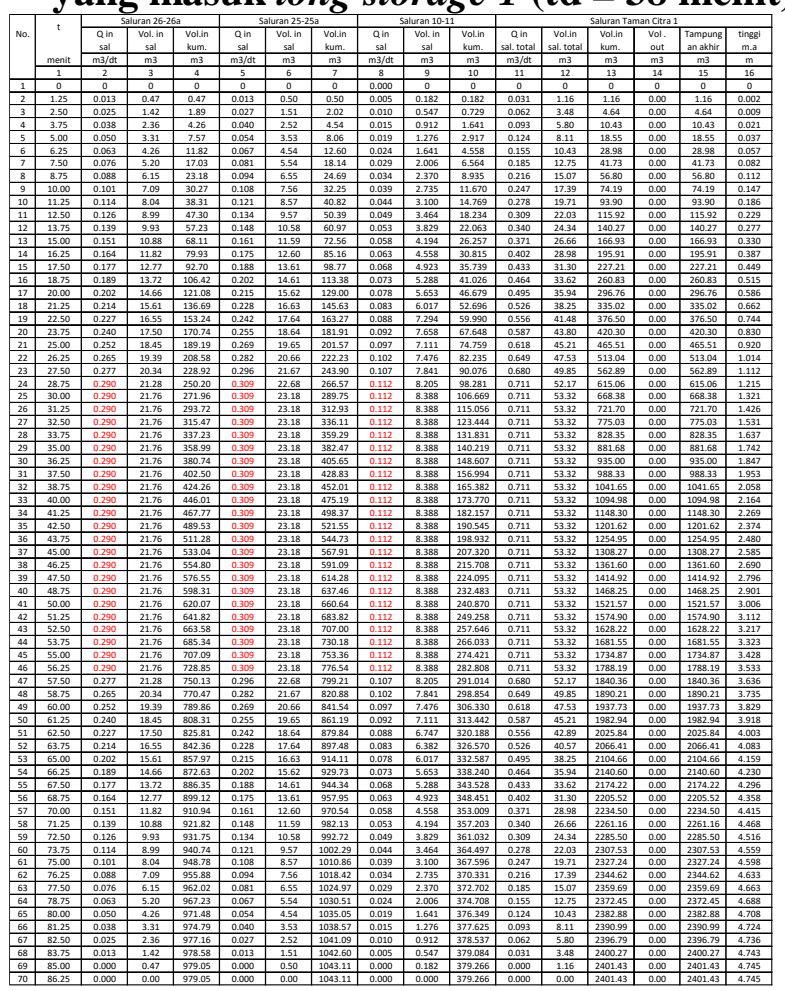

*Sumber : Hasil Perhitungan 


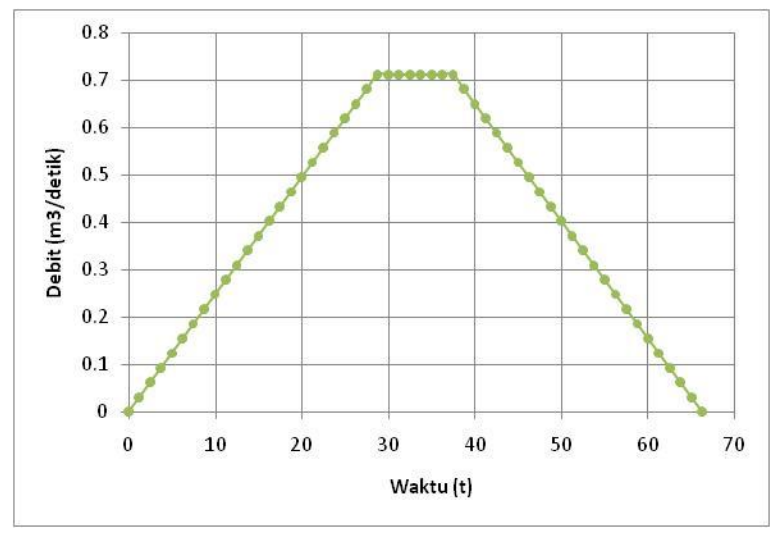

Grafik 3.3 Debit limpasan menuju long storage 1 (Saluran Taman Citra 1) $[\mathbf{t d}=38$ menit $]$

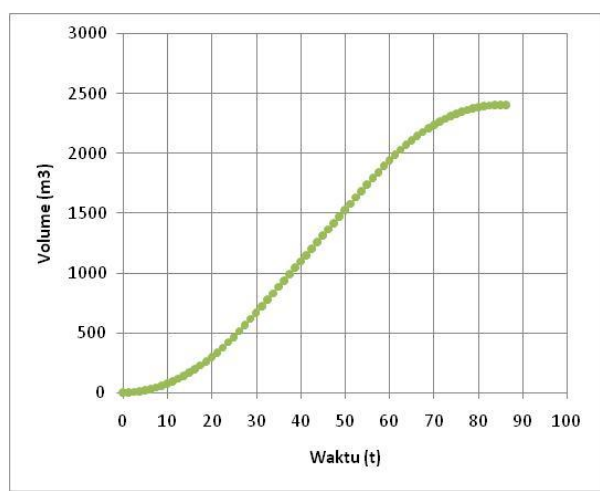

\section{Grafik 3.4Volume limpasan menujuLong storage 1 (Saluran Taman Citra 1) $[\mathrm{td}=38$ menit $]$}

Dari perhitungan di atas diperoleh hasil sebagai berikut:

\section{Tabel 3.6. Hasil perhitungan hidrograf} limpasan yang masuk ke long storage 1

\begin{tabular}{|c|c|c|c|c|}
\hline No & $\begin{array}{c}\text { Waktu Lama Hujan (td) } \\
\text { menit }\end{array}$ & $\begin{array}{c}\text { Volume } \\
(\mathrm{m} 3)\end{array}$ & $\begin{array}{c}\text { tinggi M.A long storage 1 } \\
\mathrm{m}\end{array}$ & Keterangan \\
\hline 1 & $\mathrm{td}=\mathrm{tc}=28$ menit & 190,04 & 1,5 & aman \\
\hline 2 & $\mathrm{td}=38$ menit & 254,65 & 1,9 & aman \\
\hline 3 & Persegi & 266.05 & 2,1 & meluap \\
\hline
\end{tabular}

*Sumber : Hasil Perhitungan

\section{Analisis Pintu Air}

Pintu air digunakan pada saat air masih dapat mengalir secara gravitasi dari longstorage. Pintu air di desain berdasarkan aliran tidak tenggelam. Pintu air hanya di buka berdasarkan bukaan pintu yang telah dihitung dengan pembatasan debit yang keluar dari kawasan.

\section{Perencanaan Bukaan Pintu}

- longstorage 1

Perhitungan pintu air direncanakan menggunakan Rumus berikut dan data dari perhitungan sebelumnya maka :

$\mathrm{Q}=0,87 \mathrm{~m}^{3} / \mathrm{dt}$ (debit yang diijinkan)

Direncanakan : 2 pintu air dengan lebar 1,2 m

$$
\begin{aligned}
\mu & =0,80 \text { (Koef. Debit) } \\
b & =2,4 \mathrm{~m}
\end{aligned}
$$

(lebar saluran-penyangga pintu=3 -0,6)

$$
\begin{aligned}
g & =9,81 \mathrm{~m} / \mathrm{dt}^{2} \\
h & =0,22
\end{aligned}
$$

$Q=\mu \cdot a \cdot \mathrm{b} \cdot \sqrt{2 \cdot g \cdot h}$

$0,87=0,80$ a $\cdot 2,4 \sqrt{2 \cdot 9,81 \cdot 0,22}$ $\mathrm{a}=0,218 \mathrm{~m}$

Dari perhitungan diatas, bukaan pintu maksimal dibuka sampai $20 \mathrm{~cm}$ yaitu dengan debit 0,87 $\mathrm{m}^{3} / \mathrm{dt}=52,2 \mathrm{~m}^{3} / \mathrm{mnt}$. Dengan demikian dimensi pintu air yang digunakan adalah $1,2 \mathrm{~m} \mathrm{x} 2,0 \mathrm{~m}$

\section{- longstorage 2}

$\mathrm{Q}=0,88 \mathrm{~m}^{3} / \mathrm{dt}$ (debit yang diijinkan)

Direncanakan : 1 pintu air dengan lebar $1 \mathrm{~m}$

$$
\begin{array}{ll}
\mu & =0,80 \text { (Koef. Debit) } \\
b & =1 \mathrm{~m} \\
g & =9,81 \mathrm{~m} / \mathrm{dt}^{2} \\
h & =0,7 \mathrm{~m} \\
Q & =\quad \mu \cdot a \cdot b \cdot \sqrt{ } 2 \cdot g \cdot h \\
0,88 & =0,80 \cdot \mathrm{a} \cdot 1 \cdot \sqrt{2} \cdot 9,81 \cdot 0,70 \\
\mathrm{a} & =0,29 \mathrm{~m}
\end{array}
$$

Dari perhitungan diatas, bukaan pintu maksimal dibuka sampai $30 \mathrm{~cm}$ yaitu dengan debit 0,88 $\mathrm{m}^{3} / \mathrm{dt}=53,4 \mathrm{~m}^{3} / \mathrm{mnt}$. Dengan demikian dimensi pintu air yang digunakan adalah $1 \mathrm{~m} \mathrm{x} 1 \mathrm{~m}$ *Sumber : Hasil Perhitungan

\section{Analisis Pompa Air}

Berdasarkan perhitungan sebelumnya volume limpasan air hujan yang terjadi di kawasan Perumahan The Greenlake Surabaya cukup besar. Sehingga dalam perencanaan sistem drainase kawasan tidak hanya bertumpu pada sistem gravitasi sebagai sarana untuk mengalirkan air ke saluran luar kawasan akan tetapi dibantu dengan adanya sistem pompa. Pompa air digunakan saat air tidak dapat mengalir secara gravitasi dari long storagedan saat pengosongan tampungan pada long storage 2. Pompa yang digunakan yaitu 
kapasitas pompa 1,5 $\mathrm{m}^{3} / \mathrm{mnt}$. Direncanakan menggunakan 1 unit pompa untuk long storage 1 dan 2 pompa untuk long storage 2. Pintu air dibuka saat air bisa mengalir secara gravitasi. Sedangkan pompa digunakan pada saat kedalaman air tidak bisa mengalir secara gravitasi.

\section{Analisa Saluran Taman Citra 1 (saluran luar kawasan)}

Analisis ini diperlukan untuk mengetahui berapa kapasitas yang mampu diterima oleh saluran Taman Citra 1.Hal ini dilakukan agar tidak membebani saluran Taman Citra 1. Sehingga long storage lyang dilengkapi dengan fasilitas pintu air dan pompa harus mengatur besar debit air yang diijinkan keluar dari long storage.Penampang memanjang P4 adalah hulu dan P14 adalah hilir.Profil P4 dan P11 adalah saluran tanah yang berpenampang trapezium. Profil titik P8-P11 terletak di Perumahan Safira dan profil P12-P14 adalah saluran yang melewati Perumahan Prambanan dengan kondisi saluran terbuat dari pipa beton, berjumlah dua buah masing-masing berukuran $120 \mathrm{~cm}$.

Berikut adalah perhitungan kapasitas saluran Taman Citra 1 (saluran luar kawasan) :

Tabel 3.7. Perhitungan fullbank Saluran Taman Citra

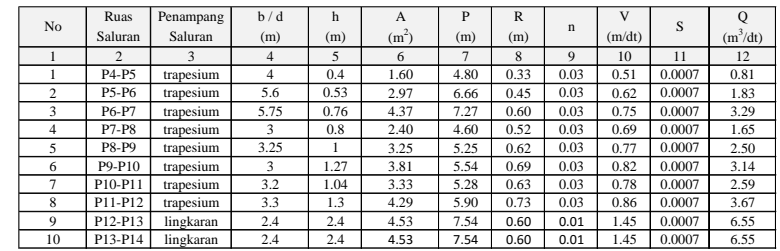

*Sumber : Hasil Perhitungan

Tabel 3.8. Dimensi dan Analisis Debit Limpasan Saluran Taman Citra 1

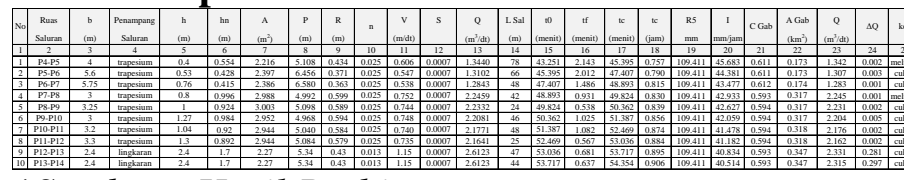

*Sumber : Hasil Perhitungan

Tabel 3.9. Dimensi dan Analisis Debit LimpasanSaluran Taman Citra $1+$ Perumahan The Greenlake

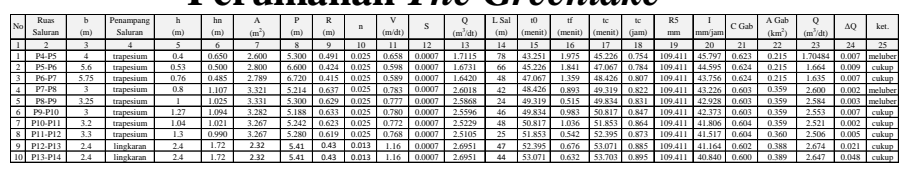

*Sumber : Hasil Perhitungan

\section{IV.PENUTUP}

\section{Kesimpulan}

Dari uraian secara umum dan perhitungan secara teknis pada bab-bab sebelumnya dapat disimpulkan bahwa :

a. PerumahanThe Greenlake dibagi 2 wilayah. Wilayah utara membuang ke long storage 1 (Saluran Taman Citra 1) dan wilayah selatan membuang ke long storage 2 .

b. Distribusi curah hujan yang memenuhi syarat adalah Distribusi Normal. Untuk hujan rencana Periode ulang

$$
\begin{aligned}
& -\quad 2 \text { tahun } \rightarrow \mathrm{R} 2=98,25 \mathrm{~mm} \\
& -\quad 5 \text { tahun } \rightarrow \mathrm{R} 5=109,41 \mathrm{~mm} \\
& -\quad 10 \text { tahun } \rightarrow \mathrm{R} 10=115,26 \mathrm{~mm}
\end{aligned}
$$

c. Perhitungan debit banjir rencana (Q) Perumahan The Greenlake dan luar kawasannya menggunakan hujan rencana periode ulang 5 tahun

1. Debit inflow yang terdapat di Saluran Taman Citra $1=0,65 \mathrm{~m}^{3} / \mathrm{dt}(\mathrm{td}=28$ menit $)$

$$
0,71 \mathrm{~m}^{3} / \mathrm{dt}(\mathrm{td}=38 \text { menit })
$$

2. Debit inflow yang terdapat pada longstorage $2=1,06 \mathrm{~m}^{3} / \mathrm{dt}(\mathrm{td}=40$ menit $)$

$$
1,27 \mathrm{~m}^{3} / \mathrm{dt}(\mathrm{td}=47 \text { menit })
$$

3. Dimensi Saluran Tersier $=0,5 \mathrm{~m} \times 0,5 \mathrm{~m}$

4. Dimensi Saluran Sekunder $=0,8 \mathrm{~m} \times 0,8 \mathrm{~m}$

5. Dimensi Saluran Primer $=1 \mathrm{~m} \times 1 \mathrm{~m}$

6. Fasilitas drainase yang dibutuhkan untuk Perumahan ini adalah:

a. Dua buah pintu air dengan dimensi 1,20 $\mathrm{m} \times 2,00 \mathrm{~m}$ pada long storage 1 dan satu buah pintu air dengan dimensi $1,00 \mathrm{~m} \mathrm{x}$ $1,00 \mathrm{~m}$ pada long storage 2 pompa dengan kapasitas $1,5 \mathrm{~m}^{3} /$ menit, untuk long storage 1 dibutuhkan satu buah pompa. Untuk long storage 2 dibutuhkan dua buah pompa.

\section{Saran}

Dari beberapa penampang pada Saluran Taman Citra 1 perlu dilakukan normalisasi salurannya. Potongan saluran yang perlu dilebarkan yaitu potongan :

1. P4-P5 dengan dimensi normalisasi $5,8 \mathrm{~m} \mathrm{x}$ $0,52 \mathrm{~m}$ dan kapasitas debit $1,85 \mathrm{~m}^{3} / \mathrm{det}$.

2. P7-P8 dengan dimensi normalisasi $3 \mathrm{~m} \times 0,8$ $\mathrm{m}$ dan kapasitas debit $2,77 \mathrm{~m}^{3} /$ det.

3. P8-P9 dengan dimensi normalisasi $3,5 \mathrm{~m} \times 1$ $\mathrm{m}$ dan kapasitas debit $2,74 \mathrm{~m}^{3} /$ det.

4. Analisis ini untuk limpasan hujan $\mathrm{td}=38$ menit. 


\section{DAFTAR PUSTAKA}

[1] Chow, V.T., 1997. Hidrolika Saluran Terbuka.Jakarta. Erlangga.

[2] Kamiana, I Made. 2010. Teknik Perhitungan Debit Rencana Bangunan Air.Palangkaraya. Graha Ilmu.

[3] Maryono, Agus. 2001. Hidrolika Terapan. Yogyakarta. Pradnya Paramita.

[4] Pengairan, Dirjen. 1986. Kriteria Perencanaan02. Jakarta. Departemen Pekerjaan Umum.

[5] Pengairan, Dirjen. 1986. Kriteria Perencanaan04. Jakarta. Departemen Pekerjaan Umum.

[6] Sofia, Fifi. 2006. Modul Ajar Drainase. Surabaya. Teknik Sipil ITS.

[7] Sosrodarsono, Ir. Suyono. 2006. Hidrologi Untuk Pengairan. Jakarta. PT Pradnya Paramita.

[8] Sosrodarsono, Dr. Suyono. 1987. Bendungan Type Urugan. Jakarta. PT Pradnya Pratama.

[9] Sujatno, Edi. 2008. Modul Ajar Hidrologi. Surabaya. Teknik Sipil ITS.

[10] Surabaya, P. 2012. Surabaya Drainage Master Plan 2012-2018. Surabaya.

[11] Suripin. 2004. Sistem Drainase Perkotaan yang Berkelanjutan. Yogyakarta.Andi.

[12] Wesli. 2008. Drainase Perkotaan. yogyakarta. Graha Ilmu. 